\title{
COMPARATIVE STUDY OF RECTALLY ADMINISTERED MISOPROSTOL AFTER SPINAL ANAESTHESIA VERSUS ROUTINE INTRAMUSCULAR OXYTOCIN FOR REDUCING BLOOD LOSS IN CAESAREAN SECTION
}

\author{
Seeta Garag1, Veena Hadi²
}

1 Professor, Department of Obstetrics and Gynaecology, KIMS, Hubli, Karnataka.

${ }_{2}^{2}$ Postgraduate Student, Department of Obstetrics and Gynaecology, KIMS, Hubli, Karnataka.

\begin{abstract}
BACKGROUND
Postpartum haemorrhage is a major cause of mortality and morbidity in pregnant women in developing countries. Caesarean section is associated with increased blood loss. Misoprostol is used as potent uterotonic agent that has been thoroughly studied in the prevention and treatment of PPH after vaginal delivery. However, role of preoperative rectal misoprostol in caesarean section for reducing blood loss is not studied much, hence this study was undertaken.
\end{abstract}

ABSTRACT

\section{MATERIALS AND METHODS}

This randomised controlled trial was performed between Jan 2017 - July 2017 on 200 high-risk pregnant women coming to labour room of Department of Obstetrics and Gynaecology, Karnataka Institute of Medical Sciences, Hubli, divided into two groups. The Group A $(n=100)$ received $400 \mu \mathrm{g}$ of misoprostol. The Group B $(n=100)$ received 10U IM oxytocin after delivery as per hospital protocol. The primary outcome measures were amount of blood loss and change in haemoglobin level $24 \mathrm{hrs}$. after surgery.

\section{RESULTS}

The mean intraoperative blood loss was significantly lower in Group A (389 $\pm 172.56 \mathrm{~mL})$ than Group B $(445 \pm 180.42 \mathrm{~mL})$. The difference between the preoperative and postoperative haemoglobin value was also significantly lower in the misoprostol group (0.84) than the oxytocin group (1.10) with $(\mathrm{p}=0.0300)$. Admissions to the neonatal intensive care unit were comparable between the two groups.

\section{CONCLUSION}

Preoperative administration of $400 \mu \mathrm{g}$ rectal misoprostol significantly reduced blood loss compared to oxytocin in caesarean section without significant side effects and it can be used as an alternative to oxytocin.

\section{KEYWORDS}

Misoprostol, Oxytocin, Caesarean Section, Postpartum Haemorrhage (PPH).

HOW TO CITE THIS ARTICLE: Garag S, Hadi V. Comparative study of rectally administered misoprostol after spinal anaesthesia versus routine intramuscular oxytocin for reducing blood loss in caesarean section. J. Evolution Med. Dent. Sci. 2018;7(11):13961399, DOI: $10.14260 /$ jemds/2018/317

\section{BACKGROUND}

Worldwide, Caesarean delivery is the most frequently performed major surgical procedure.(1) Bleeding is still the major cause of mortality and morbidity in postpartum period. World Health Organisation (WHO) has reported 585,000 maternal deaths each year. $25 \%$ of cases die from postpartum bleeding. Mean amount of blood lost is $500 \mathrm{~mL}$ during normal vaginal delivery, $1000 \mathrm{~mL}$ in caesarean section and $3500 \mathrm{~mL}$ during caesarean hysterectomy.(2) Caesarean delivery is associated with an increased risk of blood loss and need for blood transfusion. Major risk factors for PPH are obstructed labour, anaemia, hypertensive disorder of pregnancy, multiple pregnancy, polyhydramnios, grand multiparty, antepartum haemorrhage, prolonged and augmented labour.(3)

'Financial or Other Competing Interest': None.

Submission 02-02-2018, Peer Review 27-02-2018,

Acceptance 05-03-2018, Published 12-03-2018.

Corresponding Author:

Dr. Seeta Garag,

Professor,

Department of Obstetrics and Gynaecology,

KIMS, Hubli-580022, Karnataka.

E-mail: seetagarag@gmail.com

DOI: $10.14260 /$ jemds $/ 2018 / 317$
Misoprostol is a synthetic PGE-1 analogue with strong uterotonic properties and it is one of the most useful drugs in obstetrics.(4) Ease of its administration through various routes, good safety profile, low cost and stable at room temperature make it a good option in resource-poor settings,(5) and in patients under anaesthesia who are vomiting, unable to take medications. Rectal misoprostol is associated with slower absorption, longer duration of action and minimal side effects, hence considered as best route for patient undergoing caesarean delivery. Rectal misoprostol administration has mean T-max of 40 - 65 minutes(6,7) and recent study showed T-max of 20 minutes which is much shorter.(8) If rectal misoprostol administered before caesarean section, the maximum effect was obtained by the end of surgery, as there is slower rate of absorption which is useful.(7,9) As there is wide gap of controversy in the results of many studies about the use of misoprostol for prevention of postpartum haemorrhage with caesarean section and also route of misoprostol administration was not fully studied; Hence this study was conducted to compare the effects of preoperative administration of rectal misoprostol with IM oxytocin on reducing blood loss in caesarean section and to study side effects. 


\section{Objective}

To compare the effects of preoperative administration of rectal misoprostol with IM oxytocin on reducing blood loss in caesarean section and to study side effects.

\section{MATERIALS AND METHODS}

This randomised controlled trial was performed between January 2017 - July 2017 on high-risk pregnant women coming to labour room of Department of Obstetrics and Gynaecology, Karnataka Institute of Medical Sciences, Hubli.

Total of 200 women of high risk pregnancy undergoing caesarean section in whom postpartum haemorrhage (PPH) anticipated were included in study, and patients were randomized in two groups, 100 in misoprostol Group and 100 in oxytocin Group using random number table generated online

(http://www.graphpad.com/quickcalcs/randomize1/).

Women were eligible for inclusion if they were undergoing emergency caesarean section under spinal anaesthesia and had at least one risk factor for PPH (Multiple pregnancy, polyhydramnios, prolonged labour, augmented labour, obesity, grand multiparity, severe preeclampsia/eclampsia, anaemia, previous caesarean section).

Women with any contraindication for the use of misoprostol (e.g. known hypersensitivity) and those with cardiovascular, hepatic or haematologic disorders were excluded. Conversion to general anaesthesia also made women ineligible. The protocol was approved by the Institutional Ethical Committee of Karnataka Institute of Medical Sciences, Hubli.

Eligibility was assessed by interview, clinical examination and review of recent investigations among women scheduled for emergency caesarean. Patients who fulfilled the selection criteria were approached for participation and written informed consent was obtained from willing participants.

Women taken up for caesarean section were given preoperatively tablet misoprostol 400 micrograms per rectum after spinal anaesthesia before painting and draping was done in Group A and in Group B IM Inj. oxytocin 10 units given after delivery of baby as per hospital protocol.

Haemoglobin level was measured before and 24 hours after the operation. Shivering, number of nausea and vomiting along the operation and up to 2 hours after it was recorded. Temperature was monitored routinely and noted in the data sheet when greater than $37.5^{\circ} \mathrm{C}$. When surgeon requested additional uterotonic agents on the basis of clinical findings during surgery, it was noted. Addition of oxytocin was considered as additional uterotonic intervention for the purpose of data analysis in misoprostol group. Inj. carboprost 250 ug IM and Inj. Methylergometrine $0.2 \mathrm{mg}$ IM were used as secondary uterotonic agents when required. Estimation of blood loss during caesarean section was determined by measuring the amount of blood collected in suction bottles after delivery of placenta plus weight of soaked towels and postpartum blood loss during the first 24 hours after surgery was assessed by weighing pads and clots. Preoperative and postoperative haemoglobin were estimated 1 hour before surgery, 24 hours after surgery respectively. The neonatal outcome including: APGAR score, the need for Neonatal Intensive Care Unit (NICU) admission and neonatal death were assessed. The side effects of postoperative fever, vomiting and shivering were recorded. After Data collection, data entry was done in Excel sheet, statistically analysed by SPSS 15 Software version. Quantitative data were shown as a mean and standard deviation and qualitative data as frequency. Independent t-test, chi-square test and Fisher's exact test were used for data analysis. $\mathrm{P} \leq 0.05$ was considered statistically significant.

\section{RESULTS}

200 women meeting inclusion criteria were enrolled in the study. The baseline demographic and obstetric characteristics were similar in the two groups (Table 1).

\begin{tabular}{|c|c|c|c|}
\hline Demographics & $\begin{array}{c}\text { Misoprostol } \\
\text { Group N=100 }\end{array}$ & $\begin{array}{c}\text { Oxytocin } \\
\text { Group N=100 }\end{array}$ & Total \\
\hline $\begin{array}{c}\text { Maternal Age } \\
{[21-32] \text { in Years }}\end{array}$ & $24.63 \pm 4.05$ & $24.75 \pm 4.06$ & $\mathrm{p}=0.8344$ \\
\hline Gravida [1-3] & $1.83 \pm 0.67$ & $1.70 \pm 0.67$ & $\mathrm{p}=0.1721$ \\
\hline $\begin{array}{c}\text { Gestational Age } \\
\text { in Weeks [37-42] }\end{array}$ & $38.98 \pm 1.26$ & $39.09 \pm 1.23$ & $\mathrm{p}=0.5323$ \\
\hline \multicolumn{3}{|c|}{ Table 1. Demographic and Obstetrics } \\
Characteristics of Participants \\
\hline
\end{tabular}

Risk factors for PPH were also found to affect similar proportions of participants in both groups (Table 2).

\begin{tabular}{|c|c|c|c|c|}
\hline Risk Factors & $\begin{array}{c}\text { Misoprostol } \\
\text { Group }\end{array}$ & $\begin{array}{c}\text { Oxytocin } \\
\text { Group }\end{array}$ & Total & P-value \\
\hline Abruption & 5 & 5 & 10 & 1.0000 \\
\hline Anaemia & 27 & 25 & 52 & 0.7150 \\
\hline $\begin{array}{c}\text { Gestational } \\
\text { Hypertension }\end{array}$ & 3 & 12 & 15 & $0.0170^{*}$ \\
\hline $\begin{array}{c}\text { Severe } \\
\text { Preeclampsia }\end{array}$ & 13 & 15 & 28 & 0.7050 \\
\hline $\begin{array}{c}\text { Antepartum } \\
\text { Eclampsia }\end{array}$ & 5 & 2 & 7 & 0.2480 \\
\hline Polyhydramnios & 4 & 0 & 4 & $0.0420^{*}$ \\
\hline $\begin{array}{c}\text { Previous Caesarean } \\
\text { Delivery }\end{array}$ & 40 & 37 & 75 & 0.6220 \\
\hline Obstructed Labour & 2 & 4 & 6 & 0.4140 \\
\hline Total & $\mathbf{1 0 0}$ & $\mathbf{1 0 0}$ & $\mathbf{2 0 0}$ & \\
\hline \multicolumn{4}{|c|}{ Table 2. Risk Factors for PPH } \\
\hline
\end{tabular}

$* \mathrm{p}<0.05$

The estimated blood loss ( $\mathrm{M} \pm \mathrm{SD}$ ) during caesarean section in misoprostol group was $389.00 \pm 172.56 \mathrm{~mL}$, in oxytocin group was $445.00 \pm 180.42 \mathrm{~mL}(\mathrm{p}=0.001)$. There was statistically significant decrease in the estimated blood loss with the misoprostol group over oxytocin group ( $\mathrm{p}=$ 0.0260) (Table 3).

\begin{tabular}{|c|c|c|c|c|c|c|}
\hline \multirow{2}{*}{ Variables } & \multicolumn{2}{|c|}{$\begin{array}{c}\text { Misoprostol } \\
\text { Group }\end{array}$} & \multicolumn{2}{c|}{$\begin{array}{c}\text { Oxytocin } \\
\text { Group }\end{array}$} & $\begin{array}{c}\text { T- } \\
\text { value }\end{array}$ & $\begin{array}{c}\text { P- } \\
\text { value }\end{array}$ \\
\cline { 2 - 6 } & Mean & SD & Mean & SD & & \\
\hline $\begin{array}{c}\text { Blood loss } \\
\text { in } \mathrm{mL}\end{array}$ & 389.00 & 172.56 & 445.00 & 180.42 & -2.2431 & $0.0260 *$ \\
\hline \multicolumn{6}{|c|}{ Table 3. Mean Blood Loss } \\
\hline
\end{tabular}

${ }^{*} \mathrm{p}<0.05$ 


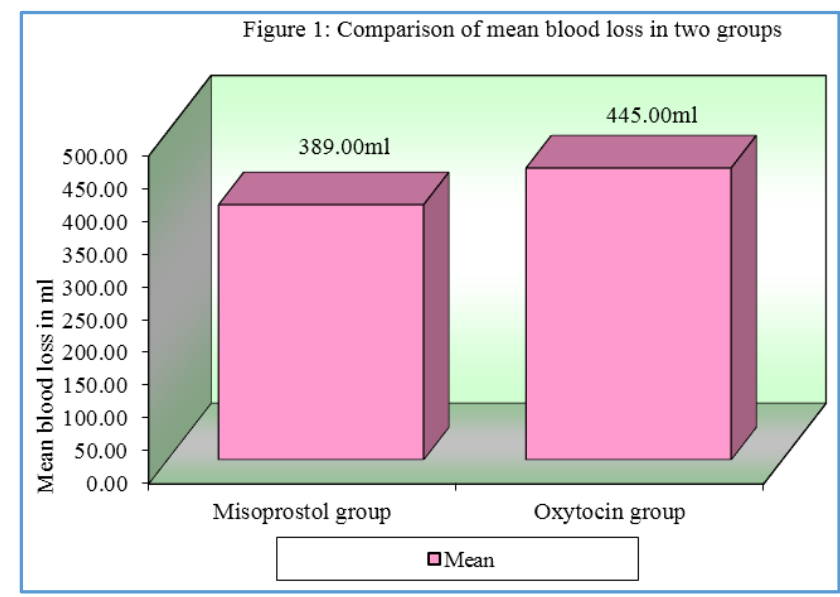

The mean difference in preoperative and postoperative haemoglobin after 24 hours was significantly less among women who received misoprostol $(0.84 \mathrm{gm})$ than among those who received oxytocin $(1.10)(p=0.001)$ (Table 4).

\begin{tabular}{|c|c|c|c|c|c|c|}
\hline \multirow{2}{*}{ Variables } & \multicolumn{2}{|c|}{$\begin{array}{c}\text { Misoprostol } \\
\text { Group }\end{array}$} & \multicolumn{2}{|c|}{$\begin{array}{c}\text { Oxytocin } \\
\text { Group }\end{array}$} & \multirow{2}{*}{$\begin{array}{c}\text { T- } \\
\text { value }\end{array}$} & P- \\
& value \\
\cline { 2 - 6 } & Mean & SD & Mean & SD & & \\
\hline Preoperative $\mathrm{Hb}$ & 10.56 & 1.44 & 10.26 & 0.81 & 1.8140 & 0.0712 \\
\hline $\begin{array}{c}\text { Postoperative } \\
\text { Hb }\end{array}$ & 9.72 & 1.31 & 9.16 & 0.83 & 3.5684 & $0.0005^{*}$ \\
\hline Changes in Hb & 0.84 & 0.70 & 1.10 & 0.94 & -2.1861 & $0.0300^{*}$ \\
\hline \multicolumn{6}{|c|}{ Table 4. Comparison of Change in Haemoglobin } \\
(gm/dL) in Two Groups \\
\hline
\end{tabular}

$* \mathrm{p}<0.05$

Additional uterotonic drugs were given to fewer women in the misoprostol group (12) than in the oxytocin group (17) $(\mathrm{p}=0.004)$ and need for blood transfusion was less in the misoprostol group (18) compared to oxytocin group (22) (Table 5).

\begin{tabular}{|c|c|c|c|c|}
\hline $\begin{array}{c}\text { Outcome } \\
\text { Measures }\end{array}$ & $\begin{array}{c}\text { Misoprostol } \\
\text { Group }\end{array}$ & $\begin{array}{c}\text { Oxytocin } \\
\text { Group }\end{array}$ & Total & P-value \\
\hline $\begin{array}{c}\text { No. of patients } \\
\text { requiring blood } \\
\text { transfusion }\end{array}$ & 18 & 22 & 40 & 0.4795 \\
\hline $\begin{array}{c}\text { Additional } \\
\text { uterotonic agent }\end{array}$ & 12 & 17 & 29 & 0.3153 \\
\hline NICU admissions & 7 & 7 & 14 & 1.0000 \\
\hline \multicolumn{4}{|c|}{ Table 5. Comparison of Outcome Measures } \\
\hline
\end{tabular}

Shivering (11), vomiting (5) and pyrexia (3) were the most frequent adverse effects noted more frequently among women receiving misoprostol. No maternal death was recorded in either group (Table 6).

\begin{tabular}{|c|c|c|c|}
\hline Side Effects & $\begin{array}{c}\text { Misoprostol } \\
\text { Group } \\
\text { N=20 }\end{array}$ & $\begin{array}{c}\text { Oxytocin } \\
\text { Group } \\
\mathbf{N = 8}\end{array}$ & $\begin{array}{c}\text { Total } \\
\mathbf{N = 2 8}\end{array}$ \\
\hline Hypertension & 1 & 0 & 1 \\
\hline Shivering & 11 & 5 & 16 \\
\hline Pyrexia & 3 & 1 & 4 \\
\hline Vomiting & 5 & 2 & 7 \\
\hline \multicolumn{3}{|c}{ Table 6. Side Effects } \\
\hline
\end{tabular}

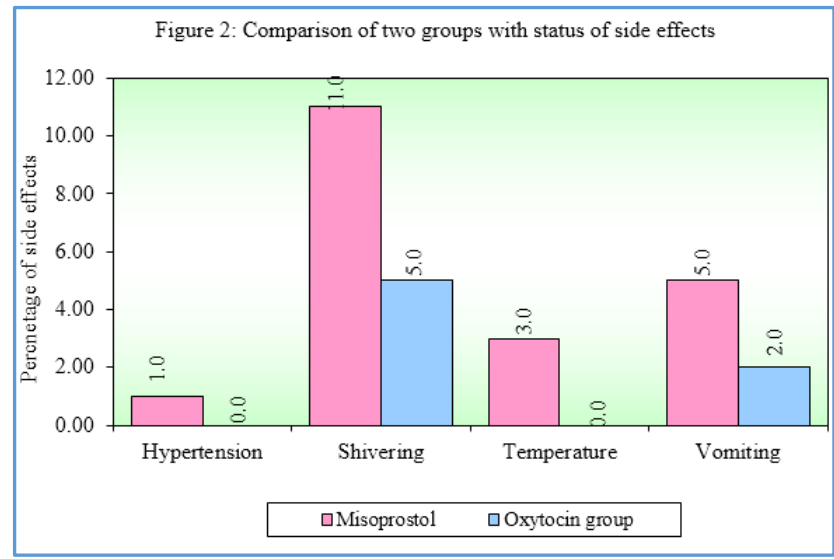

In one case of misoprostol group, hypertension was noted. Overall, the incidence of adverse effects was higher among women who received misoprostol. However, most adverse effects were self-limiting and subsided with simple measures such as covering women with blankets for shivering and cold sponging for pyrexia. Pharmacological agents were not required for any of these conditions.

\section{DISCUSSION}

In this study, we compared rectal misoprostol with an intramuscular injection of oxytocin administration in assessing blood loss in caesarean section. We found there is significant difference $(\mathrm{p}<0.05)$ of intraoperative blood loss and change in post-operative haemoglobin level in misoprostol group compared to oxytocin group. Our study was similar to study done by Alwani $\mathrm{M}$ et al from India, Fazel MR et al from Iran. Fazel et al 2 compared rectal misoprostol with IV oxytocin usage in caesarean section, blood loss was $578 \pm 185 \mathrm{~mL}$ and $630 \pm 213 \mathrm{~mL}$ respectively. Change in haemoglobin level in two groups was not statistically significant. Alwani $\mathrm{M}$ et al(10) compared rectally administered 600 ug misoprostol after spinal anaesthesia with intramuscular oxytocin during caesarean section, found no significant difference in two groups regarding change in postpartum haemoglobin, need for blood transfusion and incidence of PPH, no significant difference in any side effects. $\mathrm{K}$ Aruna Kumari et al assessed the impact of pre-operative $200 \mu \mathrm{g}$ per rectal misoprostol on blood loss during and after caesarean delivery found mean intraoperative and postpartum blood loss was lower in the study group than the control group: $374 \pm 69.9 \mathrm{~mL}$ and $131 \pm 31.8 \mathrm{~mL}$ versus $401 \pm$ 79.9 and $145 \pm 35.6 \mathrm{~mL}$ respectively and concluded that preoperative administration of $200 \mu \mathrm{g}$ rectal misoprostol significantly reduced blood loss related to elective caesarean delivery. Hesham M Borg et al(11) compared the effectiveness of the rectally administered misoprostol pre-operative with post-operative period in minimising intraoperative blood loss and prevention of postpartum haemorrhage in caesarean delivery found estimated blood loss $(\mathrm{M} \pm \mathrm{SD})$ in preoperative group was $372.33 \pm 25.997 \mathrm{~mL}$, in postoperative group was $722 \pm$ $34.089 \mathrm{~mL}(\mathrm{p}=0.001)$ and haematocrit value after caesarean section was also significantly lower in postoperative group than in preoperative group I $(\mathrm{p}=<0.001)$ and both groups were not different in terms of side-effects. Vimala et al ${ }^{\{12\}}$ compared sublingual misoprostol $400 \mu \mathrm{g}$ with oxytocin found that oxytocin group has significantly more intraoperative bleeding and there was no significant differences in post- 
operative haemoglobin level. In our study, shivering was observed in $11 \%$ of cases in misoprostol group and $5 \%$ in oxytocin group. Alwani $\mathrm{M}$ et al showed shivering in $7 \%$ of patients in misoprostol and $1 \%$ in oxytocin group. Fazel et al reported shivering was significantly more common in misoprostol group. Vimala et al reported shivering in $26 \%$ and $4 \%$ in patients with $400 \mu \mathrm{g}$ of sublingual misoprostol group and oxytocin group respectively. Chaudhuri et al reported $8.3 \%$ and $1.1 \%$ in the misoprostol and oxytocin groups respectively. Shivering is of different rate due to use of different routes of administration of drugs, operation room temperature and fluids used during the procedure. In our study vomiting was seen in $5 \%$ of patients who received misoprostol and $2 \%$ with oxytocin, pyrexia was seen in $3 \%$ in misoprostol group and $1 \%$ with oxytocin group. The differences were statistically not significant. Previous studies have reported similar findings.

\section{CONCLUSION}

Rectal misoprostol is a good alternative uterotonic for patients undergoing caesarean section for prevention of $\mathrm{PPH}$ with minimal side effects and longer duration of action, especially in resource poor countries with high maternal mortality and morbidity.

\section{REFERENCES}

[1] Betrán AP, Merialdi M, Lauer JA, et al. Rates of caesarean section: analysis of global, regional and national estimates. Paediatr Perinat Epidemiol 2007;21(2):98-113.

[2] Fazel MR, Samimi M, Fakharian E. A comparison of rectal misoprostol and intravenous oxytocin on hemorrhage and homeostatic changes during cesarean section. Middle East J Anaesthesiol 2013;22(1):41-6.

[3] Chaudhuri P, Majumdar A. Sublingual misoprostol as an adjunct to oxytocin during cesarean delivery in women at risk of postpartum hemorrhage. Int J Gynecol Obstet 2015;128(1):48-52.
[4] Chong YS, Su LL, Arulkumaran S. Misoprostol: a quarter century of use, abuse, and creative misuse. Obstet Gynecol Surv 2004;59(2):128-40.

[5] Gupta B, Jain V, Aggarwal N. Rectal misoprostol versus oxytocin in the prevention of postpartum haemorrhage-a pilot study. Int J Gynecol Obstet 2006;94(Suppl 2):S139-40.

[6] Meckstroth KR, Whitaker AK, Bertisch S, et al. Misoprostol administered by epithelial routes: drug absorption and uterine response. Obstet Gynecol 2006;108(3 Pt 1):582-90.

[7] Ragab A, Barakat R, Alsammani MA. A randomized clinical trial of preoperative versus postoperative misoprostol in elective caesarean delivery. Int J Gynecol Obstet 2016;132(1):82-4.

[8] Tang OS, Gemzell-Danielsson K, Ho PC. Misoprostol: pharmacokinetic profiles, effects on the uterus and side-effects. Int J Gynecol Obstet 2007;99(Suppl 2):S160-7.

[9] Mirteimouri M, Tara F, Teimouri B, et al. Efficacy of rectal misoprostol for prevention of postpartum hemorrhage. Iran J Pharm Res 2013;12(2):469-74.

[10] Alwani M, Singh S, Thakur R, et al. A randomized study comparing rectally administered misoprostol after spinal anesthesia versus intramuscular oxytocin for prevention of postpartum hemorrhage in caesarean section. Int J Reproduction, Contraception, Obstetrics and Gynecology 2014;3(3):512-5.

[11] Borg HM, Dawood AS. Pre-operative or post-operative misoprostol in caesarean delivery: does it differ? EC Gynaecology 2017;3:411-9.

[12] Vimala N, Mittal S, Kumar S. Sublingual misoprostol versus oxytocin infusion to reduce blood loss at cesarean section. Int J Gynecol Obstet 2006;92(2):10610. 